\title{
QUÍ-BOT-H2O CHALLENGE: INTEGRATION OF COMPUTATIONAL THINKING WITH CHEMICAL EXPERIMENTATION AND ROBOTICS THROUGH A WEB-BASED PLATFORM FOR EARLY AGES INCLUDING GENDER, INCLUSIVE AND DIVERSITY PATTERNS
}

\author{
M.I. Tarrés-Puertas, J. Merino-Millo, A.D. Dorado \\ Universitat Politècnica de Catalunya (UPC) (SPAIN)
}

\begin{abstract}
Quí-Bot- $\mathrm{H}_{2} \mathrm{O}$ is a research project in teaching innovation and scientific dissemination that joins two disciplines with high potential and demand of professionals in our society: chemistry and programming. The project includes the design of a set of activities with robots to solve several chemical experiences and programming challenges adapted to the Spanish academic curriculum of early childhood education according to ORDER ECI/3960/2007. The Quí-Bot-H2O Project has been included in the gender equality lines of action of the two reference territorial public administrations for UPC in Manresa (Bages County Council and the Manresa City Council). The Spanish Ministerio de Economía y Competitividad supports the Quí-Bot- $\mathrm{H}_{2} \mathrm{O}$ challenge under Grant FECYT2021-15626, Line of action 2. Education and scientific vocations (2nd place out of 63 awarded and 150 denied).
\end{abstract}

Keywords: STEM, robotics, diversity, inclusion, teaching, gender, stereotypes, diversity, education, innovation.

\section{INTRODUCTION}

The main goal of the QUI-BOT- $\mathrm{H}_{2} \mathrm{O}$ is the development and implementation of robots capable of performing real chemical experiments through user-programmable commands, thus bringing programming and chemistry closer to students. The programming is done intuitively through a web environment designed explicitly to attract both boys and girls from early childhood education. Chemical experiments are small-scale reproductions of robots used in Industry 4.0 that simulate basic industrial processes, without risk or danger to users. Fig. 1 summarizes the main components of the project.

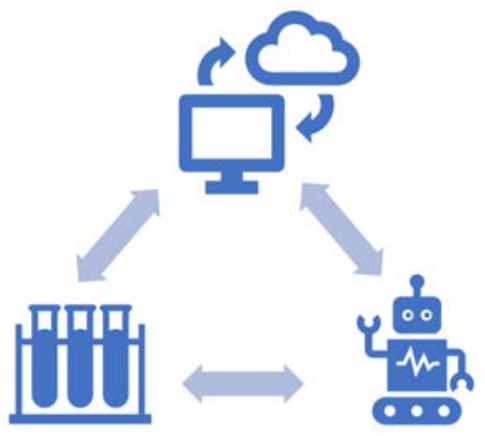

Figure 1. Visual representation of the Quí-Bot-H2O Project.

Two main reasons motivate the Quí-Bot-H2O project. First, the great demand for professionals in IT (Telecommunications and Technology) and Industry by companies in the coming years, according to national studies (see for example the InfoJobs report, [1] , and the Barcelona Chamber of Commerce $2020,[2])$, underlines the need for strategies to increase the number of professionals in STEM and to promote women in scientific careers. Secondly, the gender gap in STEM university studies is persistent year after year. According to the latest data and figures report from the Spanish university system (Ministry of Universities, 2021), in the 2018-2019 academic year, women represented only $24.8 \%$ of people enrolled in engineering and architecture, $4 \%$ less than the previous year. See the works of [ $[3]$.

Nowadays there are numerous educational projects involving robotics, such as Lego Mindstorms or Lego competitions (see for example the works of $[\underline{4}, \underline{5}, \underline{6}]$ ). These activities are basically focused on mechanical engineering projects, computer programming and soft skills such as teamwork. However, 
there is currently a great national gap in the integration of robotics applied to other disciplines such as chemistry. In this project we seek to bring significant value by joining learning chemistry and programming using robotics with the aim to attract boys and girls to STEM studies at early ages. Our proposal arises from a very satisfactory international experience at Stanford University in charge of the Department of Bioengineering led by researcher Ingmar H. Riedel-Kruse [7].

Our research follows a method including both analytic processes and empirical experimentation:

- Design of a set of activities with personalized robots by age with their corresponding chemical experiences and programming challenges adapted to Spanish academic curricula: 1) Early Childhood Education (Spanish curriculum set in ORDER ECl / 3960/2007), [9], where the ability to know and assess the basic components of the natural environment and some of their relationships, changes and transformations through simple experiments based on color changes; 2) Spanish Primary Education as established by Royal Decree 126/2014, [10], for example, classify substances and products based on the measurement of their properties such as conductivity, temperature or $\mathrm{pH}$; and 3) Spanish Compulsory Secondary Education according to Decree 187/2015 DOGC no. 6945, [11], that establishes the contents and evaluation of physics and chemistry and technology (common in spanish 2nd and 3rd ESO), such as, for example, relating the applied techniques with the methods of separating mixtures used in everyday industrial contexts, such as in the kitchen or in the recycling of materials.

- Carrying out pilot tests of the activities in small groups in order to test the designed activities. Carried out in a minimum of 5 groups corresponding to each of the educational ages between P5 and 2nd ESO. For the levels of early childhood education, the activities will be carried out in Lab0_6 of the UManresa (experimentation laboratory for scientific education in the early ages). In the case of later levels, primary education and 1st and 2nd ESO, they will be carried out in the CodeLearn and La Codornella academies, participants in the project and in which extracurricular activities are carried out with robotics. From the set of pilot tests, audiovisual material will be collected and added to an Open Course Ware (OCW) platform of free access (open science) created for this purpose, a data management platform and a support App. Interaction with robots by App facilitates the sharing of experiences between users and agents participating in the project. The design of the web and the App follows the principles of user-centered design, inclusive design and that takes into account the functional diversity of its users.

- Assessment of the results (classified in terms of age, gender and social environment) and the quantitative and qualitative evaluation of the impact of the project before and after participation in the activities. Corrections will be applied based on the experiences of the pilot tests.

- Implementation of the project in the classrooms that will be carried out through the training of teachers in schools and institutes and their incorporation into the training offer of the Department of Education. The training seeks to provide teachers with the tools that facilitate the use of the material, the application of the project and even the adaptation according to the educational project of their center. The dissemination of the activities among the educational centers will be completed with the collaboration of experts from the sector in the form of webinars and / or conferences, which at the same time make visible female references in STEM sectors. For example, Nuria Infiesta, $\mathrm{COO}$ and Founder of Yasyt Robotics [12], an expert company in social robotics, and with numerous projects for the assistance and telepresence of dependent people with voice recognition devices. In addition, with the aim of encouraging the participation of schools and centers, it is counting on the collaboration of the multinational Hewlett-Packard to jointly design a school contest that will reward the resolution of the challenges launched using the Chemical-Bot-H2O design. HP already has experience in conducting competitions of this type at an international level, for example HP CodeWars [13], based on educational robotics for high school students. Hence the interest of the multinational to collaborate in a project whose target audience is also the students of kindergarten and primary education.

\section{METHODOLOGY}

Quí-Bot- $\mathrm{H}_{2} \mathrm{O}$ project is structured in the following phases:

- Phase 1: Preparation of the activity with robots and sensors, technical advice and equipment for handling and control of the robots. 
- Phase 2: Testing of activities and fine-tuning of activities in controlled environments through expert advice.

- Phase 3: Search for experts in related fields to deepen the applicability of robotics and chemistry.

- Phase 4 and 5: Design of the OCW website and the App.

- Phase 6: Dissemination of activities and use of technological means for the dissemination of activities (promotional video, photographs, brochure design and dissemination material). To encourage the participation of schools and institutes at the state level, a new competition will be created by Hewlett Packard, following the philosophy of HP CodeWars. The dissemination will be accompanied by talks by experts confirmed in Phase 3 that give visibility to women in the STEM areas involved.

- Phase 7: Carrying out the activity for the teaching staff of schools and institutes

- Phase 8: Evaluation of results, includes the exhaustive analysis of the qualitative and quantitative impact of the project.

The project is endorsed by the experience accumulated in educational innovation initiatives in chemistry carried out by the Chemical Engineering faculty of the Spanish UPC Campus Manresa, which are summarized as an example in: Chemistry Olympics, Erasmus ScienceGirls Project 2016-2018, Premium Talent Program of Chemical Engineering for Central Catalonia (TEQxC2) and Time of Chemistry (awarded by the International Competition 'Science in Action 2019' and with the support of the chemistry section of the Institute of Catalan Studies). Likewise, in the field of programming and robotics there are the experiences of 'Tiempo de Robots' 2019 and International Girls in ICTDay. Finally, highlight as inspiration the real scientific project in chemical engineering 'Biometallum' [8] led by the co-responsible author of the project and applicable to Industry 4.0.

This proposal is based on the experience of 22 members ( $59.1 \%$ women) and involves 15 entities and institutions following the quadruple helix model (open innovation 2.0) and that includes academia (research centers and universities), companies, public administration and citizenship (associations). 3 universities (public and private) participate in the project: UPC [14], UManresa-UVic-UCC [15] and UAB [16]; 2 public administrations; a multinational (HP); 2 business associations; 2 foundations; 1 cooperative and 2 training centers. It also has the support of the Department of Education of the Generalitat of Catalonia. The preparation and testing of the activities will be developed, from the technical point of view, by the research faculty of chemical engineering, electronics, ICT and mathematics of the Department of Mining, Industrial and ICT Engineering of the UPC, [18]. The pedagogical adaptation for the age groups will be carried out with the collaboration of experts in the field of the research group in education, neuroscience, experimentation and learning (GRENEA), [17], of UManresa. Effective communication, considering the target audience for the project, will be designed by experts, members of the UVic-UCC communication department, [15]. There will also be the experience of the UAB professor, Dr. María Pilar Dellunde [16], a researcher at the Artificial Intelligence Research Institute (IIIACSIC), [19], who will contribute to the development of an ethical code for the use of robots in the classroom and a reflection on the relationship of boys and girls with robots enhancing their creativity.

\section{RESULTS}

The Lego-based robot prototype design includes sensors and actuators to make it more attractive to students and easy-to-use to students and teachers. Additional material has been designed using free software and created with a 3D printer, together with standard low-cost chemistry consumables such as syringes and pipettes. The software and web framework to control the robot use open-software components. Further material covers the steps to be able to carry out the assembly of the robot from scratch, together with a smart web interface that controls the robot. The ad hoc design of the Quí-bot$\mathrm{H}_{2} \mathrm{O}$ web interface follows the principles of user-centered design, user-friendly, and inclusive design and takes into account the functional diversity of its users. The activities require simple equipment (PCs, tablets, mobile phones) with an Internet and Bluetooth connection. The Quí-bot- $\mathrm{H}_{2} \mathrm{O}$ web platform is compatible with the latest versions of the most used operating systems and well-known browsers, such as Google Chrome or Firefox.

Quí-Bot- $\mathrm{H}_{2} \mathrm{O}$ provides a shell script that will automatically install all software components with no effort and is feasible for teachers. Builders of all ages will love building and coding their fully-functional robot to play with chemical experiments or complete tasks included in their Spanish academic curriculum. This educational STEM robot makes engineering, programming, and science fun for boys and girls who 
build and/or use it. With the aim that the project covers all educational levels, tests and continuous improvement of hardware and software through feedback will be taken into account.

Our work is supported by the integrated collaboration of several universities specialized in technology and science (UPC, UAB) and in pedagogy and communication (UManresa, UVic-UCC), as well as economic and social agents (administrations, business fabric and citizenship). The group of collaborating entities has a common objective: the promotion of education and scientific technical vocations from an early age, especially in the female gender, which transcends over time to reduce the imbalance between the need for professionals and the lack of vocations.

\section{CONCLUSIONS}

Future work includes assessment of the results (classified in terms of age, gender and social environment) and the quantitative and qualitative evaluation of the impact of the project before and after participation in the activities. Corrections will be applied based on the experiences of the pilot tests. Implementation of the project in the classrooms, that will be carried out through the training of teachers in schools and their incorporation into the training offer of the Department of Education.

Finally, it should be noted that the actions of the Quí-Bot- $\mathrm{H}_{2} \mathrm{O}$ project align with the Sustainable Development Goals: Quality Education, Gender Equality, Industry, Innovation, and Infrastructure and Reduction of Inequalities, and is part of the International Year of Creative Economy for Sustainable Development, 2021.

\section{ACKNOWLEDGEMENTS}

The Quí-Bot- $\mathrm{H}_{2} \mathrm{O}$ challenge is supported by the Spanish Ministerio de Economía y Competitividad under Grant FECYT2021-15626, Line of action 2. Education and scientific vocations.

\section{REFERENCES}

[1] Infojobs. Presentation of the InfoJobs-ESADE 2020 Annual Report, Accessed June 3, 2021. Retrieved from https://orientacion-laboral.infojobs.net/presentacion-informe-anual-infojobs-esade2020

[2] Barcelona Chamber of Commerce. 2021 Report of the most demanded professions and the highest salaries in Catalonia, Accessed June 3, 2021. Retrieved from https://premsa.cambrabcn.org/content/la-cambra-i-infojobs-posen-a-disposicio-dels-estudiantslinforme-2021 -de-les-professions-mes-demandades-i-amb-major-sou-a-catalunya/

[3] Spanish Ministry of Science and Innovation. Scientific Report Women in Science 2021, Accessed June 3, 2021. Retrieved from https://www.ciencia.gob.es/stfls/MICINN/Ministerio/FICHEROS/Cientificas_en_Cifras_2021.pdf

[4] Wafa Johal, Yu Peng, and Haipeng Mi. 2020. Swarm Robots in Education: A Review of Challenges and Opportunities. In Proceedings of the 8th International Conference on HumanAgent Interaction (HAI '20). Association for Computing Machinery, New York, NY, USA, 272-274. Retrieved from https://doi.org/10.1145/3406499.3418755

[5] Fagin, Barry \& Merkle, Laurence. (2003). Measuring the effectiveness of robots in teaching computer science. ACM Sigcse Bulletin. 35. 307-311. Retrieved from https://doi.org/10.1145/792548.611994

[6] Alex Barco, Rhea Montgomery Walsh, Avram Block, Kate Loveys, Andrew McDaid, and Elizabeth Broadbent. 2019. Teaching social robotics to motivate women into engineering and robotics careers. In Proceedings of the 14th ACM/IEEE International Conference on Human-Robot Interaction (HRI '19). IEEE Press, 518-519.

[7] Gerber LC, Calasanz-Kaiser A, Hyman L, Voitiuk K, Patil U, et al. (2017) Liquid-handling Lego robots and experiments for STEM education and research. PLOS Biology 15(3): e2001413. Retrieved from https://doi.org/10.1371/journal.pbio.2001413

[8] AGAUR University and Research Grants Management Agency 2018, Catalonia, Spain. Optimization and validation of a prototype on a biotechnological basis for the recovery of valuable metals in electronic waste. 
[9] State agency official state bulletin. Ministry of Spain Order ECI / 3960/2007, of December 19, which establishes the curriculum and regulates the organization of early childhood education. Accessed July 2, 2021. Retrieved from https://www.boe.es/eli/es/o/2007/12/19/eci3960.

[10] State agency official state bulletin. Ministry of Spain Order Royal Degree 126/2014, Accessed July 2, 2021. Retrieved from https://www.boe.es/buscar/pdf/2014/BOE-A-2014-2222-consolidado.pdf

[11] DECREE 187/2015 Official Bulletin of Government of Catalonia, Spain, Accessed July 2, 2021. Retrieved from https://portaldogc.gencat.cat/utilsEADOP/PDF/6945/1441278.pdf

[12] HPCodeWars project, Accessed July 2, 2021. Retrieved from https://hpcodewarsbcn.com/

[13] YASYT Robotics, Accessed July 2, 2021. Retrieved from https://www.yasyt.com/en/

[14] Manresa Knowledge Campus. UPC university, Accessed July 2, 2021. Retrieved from https://www.upc.edu/en?set_language=en

[15] UManresa University, Accessed July 2, 2021. Retrieved from https://www.umanresa.cat/en/umanresa-uvic-ucc

[16] UAB Barcelona University, Accessed July 2, 2021. Retrieved from https://portalrecerca.uab.cat/en/persons/pilar-dellunde

[17] Grenea Research Group, UManresa, Accessed July 2, 2021. Retrieved from http://recerca.umanresa.cat/grenea/en/

[18] Department of Mining, Industrial and ICT Engineering, Manresa Knowledge Campus. UPC, Accessed July 2, 2021. Retrieved from https://emit.upc.edu/en

[19] Artificial Intelligence Research Institute, Accessed July 2, 2021. Retrieved from https://www.iiia.csic.es/en-us/ 